\title{
JUSTIÇA AMBIENTAL E DESENVOLVIMENTO: UM DIALOGO POSSIVEL?
}

\section{${ }^{1}$ Letícia Albuquerque}

\section{RESUMO}

O discurso do desenvolvimento direcionado aos países periféricos foi amplamente aceito e incentivado pelos internacionalistas, sobretudo no pós Segunda Guerra Mundial a partir dos programas da ONU. Em 1972, com a realização da Conferência de Estocolmo sobre Meio Ambiente e Desenvolvimento Humano, o tema entra no cenário internacional, sem contudo representar um melhora das condições ambientais. Assim, o objetivo do presente artigo é demonstrar que apesar do esverdear da agenda internacional, esta continua desconsiderando parâmetros de justiça social e ambiental, reforçando um modelo de desenvolvimento excludente e gerador de conflitos. A pesquisa é feita através da analise documental e bibliográfica.

Palavras-chave: Desenvolvimento, Justiça ambiental, Direitos humanos

\section{JUSTICIA AMBIENTAL Y DESARROLLO: UN DIÁLOGO POSIBLE?}

\section{RESUMEN}

El discurso del desarrollo dirigido a los países de la periferia fue ampliamente aceptad por los internacionalistas, sobre todo en el periodo posterior a la Segunda Guerra a partir de los programas de la ONU. El objetivo de este artículo es demostrar que a pesar de la "ecologización" de la agenda internacional, esta continúa sin tener en cuenta los parámetros de la justicia social y ambiental, lo que refuerza un modelo de desarrollo generador de conflictos. La investigación se realizó a través del análisis documental y bibliográfico.

Palabras-claves: Desarrollo, Justicia ambiental, Derechos humanos

\footnotetext{
1 Doutora pela Universidade Federal de Santa Catarina - UFSC, Santa Catarina (Brasil). Professor pela Universidade Federal de Santa Catarina - UFSC, Santa Catarina (Brasil). Coordenadora do Observatório de Justiça Ecológica (OJE), grupo de pesquisa cadastrado no CNPq E-mail: let albuquerque@yahoo.com.br
} 


\section{CONSIDERAÇOES PRELIMINARES}

O discurso do desenvolvimento direcionado aos países periféricos foi amplamente aceito e incentivado pelos internacionalistas, sobretudo no pós Segunda Guerra Mundial a partir das diretrizes e programas da Organização das Nações Unidas (ONU). Em 1972, com a realização da Conferência de Estocolmo sobre Meio Ambiente e Desenvolvimento Humano, organizada pela ONU, o binômio desenvolvimento x meio ambiente entra no cenário internacional, dando início a uma série de conferências, declarações e tratados internacionais sobre o tema. No entanto, a criação de espaços na agenda política internacional vinculados ao desenvolvimento e ao meio ambiente, bem como o aumento do número de tratados e declarações internacionais não reflete uma melhora das condições ambientais do planeta. $\mathrm{O}$ movimento por justiça ambiental surge, de certa forma, como uma resistência ao discurso desenvolvimentista dominante, denunciando que não é a falta de desenvolvimento que causa a pobreza e origina a violência que produz a destruição da natureza e das formas de vida, mas sim o próprio processo de desenvolvimento. Assim, o objetivo do presente artigo é demonstrar que apesar do acréscimo do tema ambiental a agenda do desenvolvimento, esta continua desconsiderando parâmetros de justiça social e ambiental, reforçando um modelo de desenvolvimento predador, excludente e gerador de inúmeros conflitos ambientais. A pesquisa é feita através da análise documental e bibliográfica.

Para tanto, na parte inicial do trabalho, será abordado o papel das Nações Unidas na inclusão do tema ambiental na agenda do desenvolvimento através das conferências mundiais organizadas pela ONU, bem como pelos documentados produzidos nas ultimas décadas em relação ao binômio meio ambiente e desenvolvimento no contexto de tais conferências. Na segunda parte será colocada à discussão à respeito da justiça ambiental ou ecológica e os novos parâmetros para a garantia da igualdade e da dignidade que irão propiciar a construção de um modelo de desenvolvimento inclusivo e solidário.

\section{A AGENDA INTERNACIONAL E A INCLUSAO DO TEMA MEIO AMBIENTE E DESENVOLVIMENTO}

No cenário internacional o espaço reservado à temática ambiental tem aumentado consideravelmente desde a Conferência de Estocolmo de 1972, o que não significa que esta ampliação da consciência do problema junto à opinião pública tenha gerado avanços expressivos. Os fatores que causaram na humanidade um aumento de percepção da chamada crise ambiental são os mais diversos, abrangendo tanto aspectos econômicos e políticos como fatores ecológicos propriamente ditos (tsunamis, enchentes e outras catástrofes naturais) (ALBUQUERQUE, 2009, p.26). 
A Conferência das Nações Unidas sobre Meio Ambiente e Desenvolvimento Humano, de 1972, é considerada um marco não só na temática ambiental, mas também na questão do desenvolvimento. Para Le Prestre (2000) a Conferência marcou uma importante etapa da ecopolítica contemporânea, pois: "se uma evolução notável teve lugar depois, o fato é que numerosas questões presentes e debatidas em 1972 continuaram a influenciar as relações entre os atores internacionais no domínio ecológico, e as tendências que se desenharam então não fizeram senão se afirmar em seguida" (LE PRESTRE, 2000, p. 174). Durante a Conferência, o debate foi pautado pelas diferentes percepções entre os países desenvolvidos e subdesenvolvidos, reforçando a chamada dicotomia Norte/Sul ${ }^{1}$. Os países do Sul defendiam a posição segundo a qual a maior poluição era a miséria, recusando-se a reconhecer o problema da "explosão demográfica" como causa de danos ambientais, conforme sustentavam os países do Norte. O Brasil exerceu um papel de destaque na Conferência como líder dos países do Sul (ALBUQUERQUE, 2009, p.26).

Um dos principais resultados da Conferência, conforme aponta Albuquerque (2009, p.27) consistiu na Declaração de Estocolmo sobre Meio Ambiente e Desenvolvimento Humano, um conjunto de 26 princípios que deveriam orientar as políticas dos Estados com relação ao meio ambiente. A Declaração de Estocolmo refletiu em parte a dicotomia dos debates que marcaram a Conferência, dando especial ênfase à promoção de melhores condições de desenvolvimento aos países do Sul. São vários os princípios que fazem referência à cooperação entre os países desenvolvidos e em desenvolvimento como instrumento de aumento das condições de desenvolvimento desses países e, consequentemente, para uma melhora das condições ambientais, como depreende-se do princípio 11 da Declaração:

As políticas ambientais de todos os Estados deveriam estar encaminhadas para
aumentar o potencial de crescimento atual ou futuro dos países em desenvolvimento
e não deveriam restringir esse potencial nem colocar obstáculos à conquista de
melhores condições de vida para todos. Os Estados e as organizações internacionais
deveriam tomar disposições pertinentes, com vistas a chegar a um acordo, para se
poder enfrentar as consequências econômicas que poderiam resultar da aplicação de
medidas ambientais, nos planos nacional e internacional. (CONFERENCIA DAS
NAÇÕES UNIDAS, 1972). ${ }^{1}$ Usualmente se utiliza a denominação geográfica Norte/Sul para dividir os países em desenvolvidos e
subdesenvolvidos. Para uma crítica a esses "geografismos", ver: LACOSTE, 1997 .

A Declaração de Estocolmo (CONFERÊNCIA DAS NAÇÕES UNIDAS, 1972) reflete também a vontade dos países do Sul em minimizar o alcance desta, conforme relata Le Prestre (2000, p. 176): "Por exigência deles, os princípios 8 e 9 afirmam que o desenvolvimento econômico é uma pré-condição para a melhoria da qualidade de vida e um remédio para a degradação do meio ambiente.” No entanto, o autor destaca que a extensão das 
medidas de cooperação internacional na questão ambiental após Estocolmo foi mais difícil do que o previsto, sobretudo por três questões: 1. o conhecimento sobre os problemas ambientais era insuficiente; 2. os custos de proteção ambiental são altos, e logo foram constatadas outras prioridades internacionais, sobretudo econômicas, que esfriaram o ânimo inicial; 3. a tendência das ONGs de se fixarem em fins irrealistas e em projetos grandiosos (LE PRESTRE, 2000, p. 178). Assim, a Conferência de Estocolmo é um marco na aproximação do debate acerca do desenvolvimento com a problemática ambiental, embora tal debate seja ainda muito pautado por questões de interesse econômico e não em uma visão mais integrada entre aspectos econômicos, sociais, culturais e naturais (ALBUQUERQUE, 2009, p.28).

O primeiro diretor executivo do Programa das Nações Unidas para o Meio Ambiente (PNUMA), Maurice Strong, durante a primeira reunião administrativa do Conselho do referido Programa, em julho de 1973, lançou a ideia de ecodesenvolvimento, que foi sendo aprimorada (ou deturpada) ao longo do tempo. Ignacy Sachs (2007), um dos maiores pensadores sobre o ecodesenvolvimento, publicou, em 1974, um texto considerado a base das ideias que conformam a noção de ecodesenvolvimento. Nesse artigo, intitulado "Ambiente e estilos de desenvolvimento", o autor atesta que o ambiente é uma dimensão do desenvolvimento e, portanto, deve ser internalizado em todos os níveis de tomada de decisão. Para tanto, deve ser estabelecida uma nova articulação entre as ciências do homem e as ciências naturais, com a finalidade de apreender a interação dos processos naturais e sociais, nos quais o homem é simultaneamente sujeito e objeto: "um sujeito consciente de pertencer à natureza e consciente do seu futuro" (SACHS, 2007, p. 56). Sachs (2007) salienta a ambiguidade do termo "meio ambiente" e as suas diversas acepções, que para ele abrangem, de um lado, os recursos naturais existentes no planeta e, de outro, a qualidade do ambiente, sendo que ambas as definições devem ser consideradas pelos planejadores de processos de desenvolvimento (ALBUQUERQUE, 2009, p.33).

Vieira (2001, p. 54) relata que a Declaração de Cocoyoc, de 1974, e o Relatório “Que Faire?”, apresentado no final do ano de 1975 pela Fundação DAG HAMMARSKJOLD atualizaram o modelo esboçado por Sachs, mas sem referir o termo ecodesenvolvimento de forma explícita. O Relatório “Que Faire?”, elaborado para a $7^{\circ}$ Conferência Extraordinária das Nações Unidas, faz referência a termos como "outro desenvolvimento" e “desenvolvimento endógeno", e seguiu a pauta da Conferência de Estocolmo, ou seja, trabalhar a dicotomia meio ambiente e desenvolvimento, demonstrando não haver incompatibilidade entre ambos, mas limites ecológicos. Outro desenvolvimento, um novo sistema de relações internacionais e a reforma das Nações Unidas são questões chaves levantadas pelo Relatório para o início de um processo de mudança do sistema internacional. Do ponto de vista da política internacional, poucos passos foram dados no sistema das Nações 
Unidas nesse sentido (ALBUQUERQUE, 2009, p.33). Por outro lado, o Relatório identificou dez pontos a serem trabalhados para reforçar essa mudança no sistema internacional no sentido de alcançar um outro desenvolvimento. São dez pontos: 1. Erradicar a pobreza; 2. Estimular a capacidade do terceiro mundo para um desenvolvimento autônomo; 3. Fortalecer as estruturas econômicas, sociais e políticas do terceiro mundo; 4. Aumentar a viabilidade de acesso aos gêneros alimentícios; 5. Reorientar a ciência e a tecnologia para outro desenvolvimento; 6. Desenvolver informação pública; 7. Redefinir as políticas de transferências internacionais de recursos; 8. Estabelecer uma autoridade internacional para gerir o patrimônio comum da humanidade; 9. Adaptar o sistema das Nações Unidas para as novas necessidades; 10. Promover o acesso à justiça e o respeito aos direitos humanos (DAG HAMMARSJKOLD FOUNDATION, 1975, p. 13).

O Relatório reconhece o conflito entre o meio ambiente e as políticas de desenvolvimento promovidas até então, destacando que, para alcançarmos um outro desenvolvimento, a preservação do meio ambiente deve andar junto com a satisfação das necessidades, que precisam, por sua vez, ser repensadas. Para os autores do Relatório, o que existe de mais harmonioso na relação entre a sociedade e o seu meio ambiente natural é a riqueza inexplorada de possibilidades. O conceito de ecodesenvolvimento resgata uma autonomia local, segundo a qual a solução de muitos dos problemas ambientais pode ser encontrada por cada comunidade nas bases dos recursos de cada ecossistema, abrindo uma vasta perspectiva de satisfação de várias necessidades, além de incluir um sentimento de controle do seu próprio destino (DAG HAMMARSJKOLD FOUNDATION, 1975, p. 37).

No entanto, o Relatório não obteve a repercussão esperada. A proposta de um outro desenvolvimento, centrado nos pilares do respeito ao meio ambiente, na autonomia local e na satisfação das necessidades, acabou perdendo espaço para a discussão que dominou a década de 1970 no cenário das Nações Unidas a respeito da Nova Ordem Econômica Internacional (NOEI). Nesse sentido, mais uma vez impera a dicotomia entre meio ambiente e economia. É possível perceber que, embora haja um discurso cada vez mais amplo no sentido de demonstrar que a busca por melhores condições ambientais deva fazer parte do desenvolvimento econômico, na prática as políticas adotadas passam ao largo dessa discussão e reforçam justamente uma incompatibilidade entre tais questões (ALBUQUERQUE, 2009, p.34).

A adoção da declaração sobre a instauração de uma nova ordem econômica internacional (NOEI), em 1974, pela Assembleia Geral das Nações Unidas, propôs o restabelecimento de regras econômicas internacionais. A adoção de tal declaração, complementada pela adoção da Declaração dos Direitos e Deveres Econômicos dos Estados, de dezembro de 1974, faz parte de uma amplo movimento: o dos países não-alinhados, 
iniciado em 1955 com a Conferência de Bandung ${ }^{2}$, quando, pela primeira vez, Estados do chamado terceiro mundo se reuniram numa conferência sem a participação dos Estados europeus, dos Estados Unidos e da União Soviética. O principal tema da Conferência foi a condenação do colonialismo, seguido da discussão a respeito da chamada coexistência pacífica. Começou, então, a surgir à ideia de que os países do terceiro mundo devem buscar uma via alternativa para o seu desenvolvimento. A Conferência de Bandung é a primeira de uma série de conferências realizadas durante a década de 1960, dando início ao movimento do não-alinhamento, que abarcou não só os países afro-asiáticos, mas também outros países do que se passou a denominar "terceiro mundo" (ALBUQUERQUE, 2009, p.35).

É importante salientar que a Conferência das Nações Unidas para o Comércio e o Desenvolvimento nasceu em 1964, o que demonstra que antes mesmo da Conferência de Estocolmo o tema do desenvolvimento já fazia parte da agenda internacional, vinculado, entretanto, ao comércio, ou seja, sem considerar a problemática ambiental. Em 1970, a Assembleia Geral das Nações Unidas proclamou, por meio da Resolução 2626/XXV, de 24 de outubro, a segunda década para o desenvolvimento a partir de uma estratégia em que o desenvolvimento deveria ser construído de maneira global e integrada (RIST, 2001, p. 234). Isso demonstra que a percepção da chamada crise ambiental foi sendo construída ao longo das últimas décadas até culminar na Conferência das Nações Unidas sobre Meio Ambiente e Desenvolvimento, no Rio de Janeiro, em 1992 (ALBUQUERQUE, 2009, p.35).

$\mathrm{Na}$ década seguinte, a comunidade internacional, preocupada com as questões econômicas internacionais, com as tensões Leste-Oeste e decepcionada com a falta de impacto das conferências internacionais, parecia se afastar das preocupações ambientalistas

\footnotetext{
${ }^{2}$ São os países asiáticos que tomam a iniciativa da Conferência de Bandung, antiga capital da Indonésia, sendo que esta conferência realiza-se num contexto muito especial: o fim das guerras da Coréia e da Indochina e o contencioso sino-indiano sobre o Tibet. (VAISSE, 1995, p. 59).
}

da década anterior (LE PRESTRE, 2000, p. 182). No entanto, a década de 1980 foi marcada por uma volta da agenda ambientalista, tanto no plano internacional como no plano interno dos Estados, o que culminou na grande Conferência das Nações Unidas sobre Meio Ambiente e Desenvolvimento, realizada em 1992 na cidade do Rio de Janeiro (ALBUQUERQUE, 2009, p. 37).

Outro marco importante na discussão entre meio ambiente e desenvolvimento e, consequentemente, na construção social da crise ambiental, é o Relatório Bruntland, ou Relatório Nosso Futuro Comum, publicado em 1987 pelas Nações Unidas, propondo uma redefinição dessa discussão e uma reconciliação entre a proteção ambiental e a promoção do desenvolvimento por meio do conceito de desenvolvimento sustentável. O Relatório foi elaborado pela Comissão Mundial sobre Meio Ambiente e Desenvolvimento das Nações 
Unidas, chefiada à época pela primeira-ministra da Noruega, Gro Harlen Brundtland. Basicamente, o documento vincula os problemas ambientais à pobreza, ou seja, os países desenvolvidos teriam políticas ambientais mais rigorosas e melhor qualidade ambiental. Portanto, devem-se proporcionar condições de crescimento econômico aos países menos desenvolvidos para que estes também alcancem sua qualidade ambiental (NOSSO FUTURO COMUM, 1998, p.21).

O termo desenvolvimento sustentável, contudo, não é uma novidade colocada pelo Relatório e pode ser considerado uma faceta da ideia de ecodesenvovimento apresentada por Sachs em 1974. A referência à expressão "desenvolvimento sustentável”, ou “desenvolvimento durável”, é feita pela primeira vez em uma reunião da União Internacional para a Conservação da Natureza (IUCN), em 1980. Montibeller Filho (2008) refere que na Conferência Mundial sobre a Conservação e o Desenvolvimento, realizada pela IUCN em Ottawa, em 1986, foi introduzido o conceito de desenvolvimento sustentável e equitativo, balizado pelos seguintes princípios: "integrar a conservação da natureza e do desenvolvimento; satisfazer as necessidades humanas fundamentais; perseguir equidade e justiça social; buscar a autodeterminação social e respeitar a diversidade cultural; manter a integridade ecológica" (MONTIBELLER-FILHO, 2008, p. 54). O Relatório Brundtland retoma esse conceito dando-lhe a seguinte definição: "desenvolvimento que responde às necessidades do presente sem comprometer as possibilidades das gerações futuras de satisfazer as suas próprias necessidades" (NOSSO FUTURO COMUM, 1998, p.9).

Embora o termo desenvolvimento sustentável passe a ser identificado com a ideia de ecodesenvolvimento, é possível afirmar que a concepção de ecodesenvolvimento elaborada por Sachs (1974) e aprimorada por outros pesquisadores do campo das ciências ambientais é mais abrangente. Enquanto o "desenvolvimento sustentável" estaria baseado em uma equidade inter e intrageracional, o "ecodesenvolvimento" pressupõe uma dinâmica sistêmica de diversos fatores no sentido de buscar um desenvolvimento que valorize o potencial dos recursos naturais e humanos em cada contexto regional específico, minimizando os custos sociais e ecológicos e promovendo a autonomia das populações locais, de acordo com os seguintes critérios: satisfação das necessidades básicas e promoção da equidade; prudência ecológica; valorização da participação e da autonomia; viabilidade econômica (VIEIRA, 1995, p.58). De qualquer forma, o Relatório Bruntland aprofundou questões sobre a sustentabilidade que fortalecerão sobremaneira as ideias lançadas pelo ecodesenvolvimento (ALBUQUERQUE, 2009, p.38).

O Relatório Brundtland, entre as suas várias conclusões, recomendou à ONU a elaboração de uma declaração universal sobre a proteção do meio ambiente e do desenvolvimento sustentável e, posteriormente, a realização de uma conferência relativa ao 
tema. Assim é que através da Resolução 44/228 de 22 de dezembro de 1989 a Assembleia Geral das Nações Unidas convoca os seus Estados-membros para a realização da Conferência Internacional de Meio Ambiente e Desenvolvimento - CNUMAD/92 - que aconteceu no Rio de Janeiro, em junho de 1992, marcando os vinte anos da Conferência de Estocolmo sobre Meio Ambiente Humano de 1972. (ALBUQUERQUE, 2006, p. 45).

A década de 1990 inicia com a realização de duas grandes Conferências das Nações Unidas sobre temas que sempre ocuparam um papel secundário nas discussões políticas internacionais: meio ambiente e direitos humanos. Em 1992 aconteceu a CNUMD e, em 1993, a Conferência de Viena sobre Direitos Humanos. Esse destaque alcançado por temas até então marginais é atribuído ao fim da Guerra Fria ${ }^{3}$, que permitiu a criação de um cenário de aproximação entre os Estados para discussão de temas de interesse global, como os direitos humanos e o meio ambiente. A CNUMD/92, também conhecida como RIO/92 ou ECO/92, é considerada uma verdadeira conferência mundial pelo número de países e representações envolvidas. Foram 178 Estados, oito mil delegados, dezenas de organizações internacionais, três mil representantes de organizações não-governamentais (ONG's) credenciadas, mais de mil ONG’s num fórum paralelo e nove mil jornalistas. Na sessão final, 103 chefes de Estado e

\footnotetext{
${ }^{3}$ Las relaciones internacionales, tal como se conocieron hasta el fin de la Guerra Fría, correspondieron a una situación que dejó de existir con la desaparición de la Unión Soviética y del mundo socialista. Desde fines de la Segunda Guerra Mundial la arena internacional estuvo dividida en dos bandos enfrentados virtualmente y un tercer espacio compuesto de Estados-naciones que, sin estar directamente comprometidos en esa rivalidad principal, de alguna o de otra manera dependían de lo que ocurriría o dejaba de ocurrir en el conflicto principal (ORTIZ, 2004, p. 155). O conflito principal ao qual se refere o autor é a rivalidade estabelecida entre o bloco capitalista, liderado pelos Estados Unidos e, o bloco comunista, liderado pela então União Soviética.
}

de governo estavam sentados ao redor de uma mesa, o que constitui a maior assembléia de chefes de governo e de Estado na história, até a celebração do $50^{\circ}$ aniversário da $\mathrm{ONU}$, no outono de 1995 (LE PRESTRE, 2000, p.201). Foram aprovados durante a realização da Conferência importantes documentos, entre os quais, a Declaração das Nações Unidas sobre Meio Ambiente e Desenvolvimento e a Agenda 21.

A Declaração sobre Meio Ambiente e Desenvolvimento é um conjunto de 27 princípios que deveriam orientar as políticas públicas dos Estados signatários com relação ao meio ambiente. É considerada um documento de consenso, mas de cunho muito mais político do que jurídico. Ficou distante daquilo que recomendava o Relatório Brundtland - uma carta que estipularia as novas diretrizes que deveriam regular as relações internacionais (ALBUQUERQUE, 2009, p.40).

Apesar dos discursos e dos documentos elaborados durante e após a CNUMD/92, que apontavam para a solução dos problemas agendados através da junção de duas idéias amplamente divulgadas e aparentemente aceitas por todos - cooperação internacional e 
desenvolvimento sustentável -, os resultados concretos contrariaram totalmente essa retórica (LEIS, 2001, p. 25). Com relação à Agenda 21, por exemplo, foi muito difícil obter fundos para o seu financiamento, o que impossibilitou a implementação do que seria o plano de ação da conferência, como já referido. Contudo, o documento representa um importante instrumento de gestão ambiental, principalmente para o estabelecimento de mecanismos de ordenamento do território com base nos pressupostos do ecodesenvolvimento, ou seja, uma gestão integrada, participativa, pro-ativa e preventiva.

Para concluir, o final da década de 1980 e a década de 1990 foram marcados pelo Relatório Brundtland e pela CNUMD/92, que colocaram em pauta o conceito de “desenvolvimento sustentável”. Rist (2001) sustenta que de qualquer forma esses dois grandes acontecimentos deram visibilidade internacional aos "problemas do meio ambiente" que são, sobretudo, os problemas que a sociedade industrial coloca ao meio ambiente, e não o inverso, como se fez acreditar muitas vezes (RIST, 2001, p. 313). Para o autor, o Relatório Brundtland, apesar de introduzir algumas questões relevantes, já mencionadas, nada mais fez do que reforçar uma "diplomacia de terminologia", principalmente em razão da difusão do termo “desenvolvimento sustentável”. A contradição não está apenas no jogo de palavras, mas nas atitudes. Rist sustenta que o “desenvolvimento sustentável” não passa de uma

\footnotetext{
${ }^{4}$ A expressão "diplomacia de terminologia" é referida para indicar o uso constante de oximoros, sobretudo em documentos internacionais. Oximoro é uma figura de linguagem que harmoniza conceitos opostos ou palavras contraditórias, como no caso, desenvolvimento sustentável.
}

camuflagem que tenta creditar à necessidade de desenvolvimento um valor supremo já reconhecido ao meio ambiente. (RIST, 2001, p. 317).

Em 2002, as Nações Unidas mais uma vez convocam os seus Estados membros para uma nova cúpula mundial sobre as questões ambientais. De 26 de agosto a 4 de setembro os Estados membros da ONU reuniram-se em Johanesburgo, África do Sul, para a realização da Conferência das Nações Unidas sobre Meio Ambiente e Desenvolvimento Sustentável, referida também como Rio +10 . Essa Conferência, embora não tenha repercutido da mesma forma como as suas antecessoras - Estocolmo/72 e Rio/92 -, não pode deixar de ser referida como um dos marcos na percepção da crise ambiental. No entanto, a Conferência acabou sendo considerada um fracasso em razão da amplitude dos temas colocados em discussão e pela falta de sistematização na abordagem desses temas. O foco da Conferência foi colocado nos seguintes temas: mudança dos padrões de produção e consumo; erradicação da pobreza; manejo de recursos naturais; desenvolvimento sustentável. A expectativa dos participantes estava na elaboração e adoção de três importantes documentos: uma declaração política com compromissos para a implementação do desenvolvimento sustentável; um programa de ação 
para orientar a efetivação dos compromissos políticos e uma compilação de novos compromissos e iniciativas para ações em esfera nacional e regional.

Contudo, o resultado da Conferência ficou muito aquém do esperado: os progressos e o comprometimento com medidas mais efetivas para a implementação de uma política ambiental internacional foram mínimos (ALBUQUERQUE, 2009, p.43).

Em 2012, o Brasil volta a sediar mais uma conferência das Nações Unidas sobre meio ambiente: Conferência das Nações Unidas sobre Desenvolvimento Sustentável ou RIO +20. Passados vinte anos da ECO92, novamente os Estados integrantes da ONU são chamados a discutir a questão ambiental em âmbito global. A Conferência foi organizada conforme a Resolução 64/236 da Assembleia Geral das Nações Unidas entre os dias 20 e 22 de junho de 2012. Reuniu mais de 100 chefes de Estado e governo de forma direta e muitos outros de forma indireta. $\mathrm{O}$ documento final da Conferência - $\mathrm{O}$ Futuro que nós queremos - foi marcado pelo compromisso assumido pela comunidade internacional em prol do desenvolvimento sustentável e aprovado pela Assembleia Geral da ONU através da Resolução 66/288 de 27 de julho de 2012. O documento reafirma os compromissos assumidos nas conferências anteriores, bem como a necessidade de combate a pobreza e as desigualdades (ALBUQUERQUE, 2014).

As Conferências das Nações Unidas sobre o Meio Ambiente apenas reforçaram os conflitos potenciais entre o crescimento econômico, a redução da pobreza e a proteção dos ecossistemas, entre o controle da poluição e a conservação dos recursos naturais ou entre as necessidades humanas e a conservação dos recursos naturais. De um lado estavam os países do Sul, reafirmando um direito ao desenvolvimento; de outro, os países do Norte, receosos de perder acesso a mercados em nome de medidas de proteção ambiental. Mesmo que tal discurso tenha alcançado o seu auge na década de 1970, ainda hoje ele faz eco nas discussões sobre o tema (ALBUQUERQUE, 2009, p.44).

$\mathrm{Na}$ contramão dessa tendência homogeneizante do desenvolvimento surgem algumas alternativas, mesmo dentro de espaços institucionais tradicionais como as Nações Unidas tal como o índice de desenvolvimento humano (IDH) elaborado no âmbito do Programa das nações Unidas para o desenvolvimento (PNUD). Esta e outras iniciativas buscam considerar algo mais que o PIB para determinar o bem-estar de um país e sua população. Nussbaum (2012, p.19) salienta que o aumento do PIB não significa necessariamente uma melhora da qualidade de vida das pessoas e nenhum informe sobre a prosperidade do conjunto de um país servirá provavelmente de consolo aqueles e aquelas cuja existência esta marcada pelas desigualdades e privações.

O enfoque das capacidades pode ser considerado uma dessas iniciativas contrahegemônicas. Nussbaum (2012, p.37) adverte que há uma certa confusão terminológica entre o enfoque das capacidades e o enfoque do desenvolvimento humano. Esclarece que o enfoque 
do desenvolvimento humano esta ligado historicamente ao PNUD e aos seus informes anuais sobre o desenvolvimento humano. Nestes informes, segundo a autora, utiliza-se o conceito das capacidades como indicador comparativo mais do que como uma base para uma teoria política normativa (2012, p.37).

Amartya Sen, através de suas obras Novo Exame das Desigualdades $e$ Desenvolvimento como Liberdade, teve um papel significativo na elaboração do desenho dos informes do PNUD, contudo, tais informes não incorporaram todos os elementos da sua teoria (pragmática e voltada para resultados), simplesmente, objetivam apresentar a informação comparativa de um modo que sirva para reorientar o debate sobre o desenvolvimento e as políticas correspondentes (NUSSBAUM, 2012, p.37). Sen utiliza o enfoque das capacidades como instrumento para realizar comparações sobre a qualidade de vida, assim como Nussbaum. No entanto, Nussbaum $(2012$, p.38) prefere o termo enfoque das capacidades ao de enfoque do desenvolvimento humano porque tem interesse nas capacidades tanto das pessoas, como nas capacidades dos animais não humanos. Para a autora o enfoque proporciona uma excelente base para a construção de uma teoria da justiça e para os direitos dos animais em geral (tanto humanos como não humanos), salienta que Sen compartilha de tal ideia, mesmo que não seja este o foco principal do seu trabalho (NUSSBAUM, 2012, p.38). A proposta de Nussbaum reforça a luta do movimento por justiça ambiental (ou ecológica) ao propor novas bases para o alcance de igual dignidade para os animais humanos e não humanos.

$\mathrm{Na}$ esteira da internacionalização do tema meio ambiente e desenvolvimento, o Vaticano, através da encíclica Laudato Si'do Santo Padre Francisco sobre o cuidado da Casa Comum, manifesta a sua preocupação com o tema: "13. O urgente desafio de proteger a nossa casa comum inclui a preocupação de unir toda a família humana na busca de um desenvolvimento sustentável e integral, pois sabemos que as coisas podem mudar"(PAPA FRANCISCO, 2015, p.12). O Papa chama atenção sobre a necessidade de renovarmos o diálogo sobre a maneira de como estamos construindo o futuro do planeta e da responsabilidade não só individual, mas também em termos de política internacional. Essa chamada ao diálogo reforça, de certa forma, as iniciativas contra-hegemônicas de desenvolvimento e o movimento por justiça ambiental e social.

\section{JUSTIÇA AMBIENTAL E DESENVOLVIMENTO: EM BUSCA DE UM DIALOGO}

O movimento por justiça ambiental é identificado na sua origem com a luta contra o racismo ambiental nos Estados Unidos iniciada na década de 1980. Condições inadequadas de saneamento e de contaminação química de locais de moradia e trabalho, bem como a disposição indevida de lixo tóxico e perigoso foi percebido como algo que afetava muito mais 
as populações negras, mestiças e de baixa renda do que o restante das pessoas. Assim, a luta por justiça das comunidades vulneráveis e expostas aos riscos da "poluição" adquire um caráter social, territorial, ambiental e de reivindicação por direitos civis.

Através de analises de riscos é identificado pelos movimentos sociais de lutas pelos direitos civis que há por parte do Estado uma aplicação desigual das leis ambientais, ocasionando uma distribuição desigual dos impactos dos acidentes ambientais por raça e renda. Assim, o movimento por justiça ambiental busca enfrentar a dimensão ambiental da injustiça social e trazer uma nova perspectiva para integrar as lutas ambientais e sociais. Essa nova perspectiva não ficou restrita aos EUA, alcançou outros países, bem como levou a discussão à respeito da distribuição desigual dos riscos ambientais para além dos movimentos sociais: alcançou o debate acadêmico e político também.

A ideia introduzida pela noção de crise ambiental de que todos, enquanto seres humanos, somos responsáveis pelas condições ambientais do Planeta, é um dos pontos de reflexão da perspectiva colocada pelo movimento de justiça ambiental. Esse cenário de crise ambiental esconde a forma como os impactos ambientais estão distribuídos tanto em termos de incidência quanto intensidade. Isso acontece, por um lado, porque o meio ambiente é visto como algo uno, escasso e homogêneo; por outro lado, porque os seres humanos, como um todo, seriam os responsáveis pelo processo de destruição das formas naturais, do ambiente e da vida.

O debate introduzido pelo movimento de justiça ambiental propõe ir além da questão da "escassez" ou do "desperdício", propõe incluir a discussão acerca dos fins pretendidos com a apropriação extensiva e intensiva do meio ambiente. Coloca os seguintes questionamentos: O que se produz? Como se produz? Para quem se produz?

A pauta de discussão dos governos e das grandes corporações ignora a destinação desproporcional dos riscos ambientais para os mais pobres e grupos étnicos vulneráveis, bem como a concentração dos benefícios do desenvolvimento à uma minoria dos habitantes do Planeta (ACSELRAD, 2009). Tal cenário acaba levando a uma situação de injustiça ambiental. A injustiça ambiental pode ser caracterizada por um fenômeno de imposição desproporcional dos riscos ambientais às populações menos dotadas de recursos financeiros, políticos e informacionais (ACSELRAD; MELLO; BEZERRA, 2009, p.9).

Dessa forma, o movimento por justiça ambiental evidencia que o discurso do desenvolvimento continua perpetrando praticas excludentes e predatórias. Contudo, tais praticas não atingem apenas os seres humanos: tanto os animais humanos como os não humanos estão sujeitos a injustiça ambiental.

Surge assim, a ideia de justiça ecológica, que procura demonstrar que os animais não humanos também deveriam estar incluídos em parâmetros de justiça. O objetivo ao introduzir 
este ponto não é estabelecer uma diferença entre justiça ambiental e justiça ecológica, pelo contrário. Ao incluir na luta por melhores condições de vida os animais não humanos, o movimento por justiça ambiental ganha um novo fôlego para continuar combatendo o modelo de desenvolvimento dominante, que apesar te ter ganho contornos "verdes" nas últimas décadas, continua desconsiderando os mais vulneráveis, sejam eles humanos ou não humanos.

Nesse sentido, Nussbaum em Fronteiras da Justiça (2013) aponta problemas atuais em termos de teorias da justiça que precisam ser enfrentados, como o problema da justiça entre nações e a justiça que devemos aos animais não humanos. Tanto a questão da justiça entre nações como a justiça que devemos aos animais não humanos dizem respeito à discussão do desenvolvimento e ao modelo de desenvolvimento dominante.

A autora (2012, p.38) propõe através do enfoque das capacidades uma aproximação da avaliação da qualidade de vida e da teorização sobre a justiça social básica. A pergunta básica do enfoque consiste em: o que é capaz de fazer casa pessoa? O enfoque concebe cada pessoa como um fim em si mesmo e não questiona somente o bem-estar total ou médio, mas também as oportunidades disponíveis para cada ser humano (NUSSBAUM, 2012, p.38). Assim, a autora propõe uma lista de capacidades básicas centrais, dirigidas tanto aos animais humanos como não humanos, como base da sua teoria de direitos políticos fundamentais.

O enfoque das capacidades esta atraindo a atenção do mundo como alternativa aos enfoques dominantes da economia e das políticas de desenvolvimento, bem como enfoque de justiça social básica dentro das nações e entre elas (NUSSBAUM, 2012, p.218).

A ideia de justiça ecológica inclui tanto a busca por justiça para os animais humanos como para os animais não humanos, de tal forma que o enfoque das capacidades auxilia na construção de novos parâmetros de reconhecimento de dignidade e igualdade para todas as formas de vida, bem como para uma adequação dos parâmetros de relação entre nações pobres e ricas a níveis mais equânimes possibilitando um diálogo em busca do desenvolvimento.

\section{CONSIDERAÇOES FINAIS}

Como evidenciado no texto o discurso do desenvolvimento direcionado aos países periféricos foi amplamente aceito e incentivado pelos internacionalistas, sobretudo no pós Segunda Guerra Mundial a partir das diretrizes e programas da Organização das Nações Unidas (ONU). Tal discurso assumiu diferentes formas ao longo das décadas de existência da ONU, principalmente ao somar ao tema do desenvolvimento às questões do meio ambiente.

Contudo, mesmo considerando os limites ambientais do planeta a lógica dominante do desenvolvimento continua ignorando as principais causas das desigualdades sociais e da exploração sem limites do meio ambiente. O cenário de injustiça ambiental é cada vez mais 
presente, tanto na esfera internacional como interna. Recentemente, o Papa Francisco, através da encíclica Laudato $\mathrm{Si}^{\prime}$ 'sobre o cuidado da Casa Comum, manifesta a sua preocupação com o tema, alertando sobre a necessidade de ação e diálogo para resultados concretos na melhoria das condições ambientais e sociais, principalmente no que tange a política internacional. No Brasil, por exemplo, o número de conflitos ambientais é cada vez maior: disputas pela terra, causadas pela expansão da mineração e do setor agrícola, conflitos pelo uso e apropriação de recursos naturais, questões envolvendo demarcação de terras indígenas e territórios quilombolas, são constantes. O modelo de desenvolvimento excludente e predador escolhido por diferentes governos ao longo das últimas décadas seguindo parâmetros internacionais hegemônicos agravaram esse cenário de conflitos.

Assim, o movimento por justiça ambiental surge como uma forma de aproximar a luta por direitos sociais a luta por melhores condições ambientais, ao denunciar que as populações vulneráveis e portanto, mais carentes em termos de reconhecimento e acesso à direitos, são aquelas que mais sofrem em termos de exposição aos riscos ambientais. É preciso levar em consideração que tais riscos não atingem apenas os animais humanos, mas também os animais não humanos. O enfoque das capacidades a partir da elaboração proposta por Nussbaum $(2012$, 2013) pode significar uma ampliação do movimento por justiça ambiental ao propor a inclusão dos animais não humanos a uma obrigação direta de justiça nossa para com relação à eles, bem como uma adequação dos parâmetros de relação entre nações pobres e ricas a níveis mais equânimes.

No Brasil, por exemplo, a construção da hidrelétrica de Belo Monte ${ }^{5}$ na região amazônica e o desastre de Mariana em Minas Gerais ${ }^{6}$, evidenciam que aqueles que sofrem em maior dimensão os riscos e efeitos ambientais são os mais vulneráveis, sejam eles humanos ou não humanos. No caso de Belo Monte, a perda de biodiversidade e os danos aos povos indígenas e as populações ribeirinhas são incomensuráveis. O empreendimento segue apesar de todos os esforços realizados pelos movimentos sociais e pelo Ministério Público Federal em demonstrar a flagrante violação à legislação vigente, bem como os impactos ambientais e sociais. Belo Monte é um excelente caso laboratório que evidencia as incongruências praticadas em nome do desenvolvimento. Em nome do desenvolvimento o governo brasileiro ignora os compromissos internacionais assumidos pelo país tanto em matéria de direitos humanos como em matéria ambiental. O paradoxo é que tanto Belo Monte, como Mariana são situações, entre tantas outras, criadas e reforçadas pela lógica econômica internacional, ainda

\footnotetext{
${ }^{5}$ Para uma analise do caso de Belo Monte do ponto de vista político e jurídico ver: VIEIRA, Flavia do Amaral. O caso de Belo Monte no Sistema Interamericano de Direitos Humanos. Dissertação de Mestrado apresentada junto ao PPGD/UFSC. Florianópolis: UFSC, 2015.

${ }^{6}$ Para uma analise preliminar do desastre de Mariana ver o relatório publicado pela ONG Justiça Global: VALE DE LAMA: relatório de inspeção em Mariana apos o rompimento da barragem do fundão. Disponível em:
} 
http://issuu.com/justicaglobal/docs/vale de_lama . Acesso em: 10 de janeiro de 2015.

dominante, que em nome do crescimento econômico e aumento do PIB das nações, desconsidera as alternativas existentes, bem como os próprios compromissos assumidos na esfera internacional. O diálogo em torno do desenvolvimento baseado em parâmetros de justiça social e ambiental, apesar de todos os esforços realizados pela comunidade internacional ainda é algo distante da realidade dos atingidos diretamente por esse sistema excludente e predador.

\section{REFERENCIAS BIBLIOGRAFICAS}

ACSELRAD, Henri. MELLO, Cecilia Campello do Amaral. BEZERRA, Gustavo das Neves. O que é justiça ambiental? Rio de Janeiro: Garamond, 2009.

AGENDA 21. Brasília: Senado Federal, 2001.

ALBUQUERQUE, Letícia. Poluentes Orgânicos Persistente: uma analise da Convenção de Estocolmo. Curitiba: Juruá, 2006.

ALBUQUERQUE, Letícia. Conflitos socioambientais na zona costeira catarinense. Tese de Doutorado apresentada junto ao PPGD. Florianópolis: UFSC, 2009.

COCOYOC DECLARATION. 1974. In: Draft report on the UNEP/UNCTAD Symposium on Patterns of Resources Use, Environment and Development Strategies. Cocoyoc, Mexico : UNEP, October 1974.

COMISSAO MUNDIAL SOBRE MEIO AMBIENTE E DESENVOLVIMENTO. Nosso Futuro Comum. Rio de Janeiro: Fundação Getúlio Vargas, 1988.

CONFERÊNCIA DAS NAÇÕES UNIDAS. Declaração de Estocolmo sobre o Ambiente Humano. Estocolmo, jun. 1972. Disponível em: <http://www.silex.com.br/leis/normas/estocolmo.htm>. Acesso em? 20 nov. 2007.

CONFERÊNCIA DAS NACOES UNIDAS SOBRE MEIO AMBIENTE E DESENVOLVIMENTO. Brasília: Senado Federal, 1992.

DAG HAMMARSJKOLD FOUNDATION. Que faire. Upssala: DHF, 1975.

JUSTIÇA GLOBAL. Vale de Lama: relatório de inspeção em Mariana apos o rompimento da barragem do fundão. Disponível em: http://issuu.com/justicaglobal/docs/vale_de_lama . Acesso em: 10 de janeiro de 2015.

LACOSTE, Yves. A geografia isso serve, em primeiro lugar, para fazer a guerra. Campinas: Papirus, 1997.

LEIS, Héctor Ricardo. Ambientalismo: um projeto realista-utópico para a política mundial. In: Meio Ambiente, Desenvolvimento e Cidadania: desafios para as ciências sociais. São Paulo: Cortez. Florianópolis: EDUFSC, 2001. 
LE PRESTRE, Philippe. Ecopolítica Internacional. São Paulo: Senac, 2000.

MONTIBELLER-FILHO, Gilberto. O Mito do Desenvolvimento Sustentável. Florianópolis: EDUFSC, 2008.

NUSSBAUM, Martha. Fronteiras da Justiça: deficiência, nacionalidade, pertencimento à espécie. São Paulo: Martins Fontes, 2013.

NUSSBAUM, Martha. Crear Capacidades: propuesta para El desarrollo humano. Barcelona: Paidos, 2012.

PAPA FRANCISCO. Encíclica Laudato Si' sobre o cuidado da Casa Comum. Vaticano: Santa Sé, 2015.

RIST, Gilbert. Développement Durable: Histoire d'une croyance occidentale. Paris: Presse de Sciences Po, 2001.

SACHS, Ignacy. Em busca de novas estratégias de desenvolvimento. In: VIEIRA, Paulo Freire. (Org.). Rumo à ecossocioeconomia: Teoria e prática do desenvolvimento. São Paulo: Cortez, 2007.

VAISSE, Maurice. As relações internacionais desde 1945. Lisboa: edições 70, 1995.

VIEIRA, Flavia do Amaral. O caso de Belo Monte no Sistema Interamericano de Direitos Humanos. Dissertação de Mestrado apresentada junto ao PPGD/UFSC. Florianópolis: UFSC, 2015.

VIEIRA, Paulo Freire. Meio Ambiente, Desenvolvimento e Planejamento. In: Vários autores. Meio Ambiente, Desenvolvimento e Cidadania: desafios para as ciências sociais. São Paulo: Cortez. Florianópolis: EDUFSC, 2001. 